Rev. Latinoam. Psicopat. Fund., São Paulo, v. 11, n. 3, p. 490-496, setembro 2008

\title{
Morel e a questão da degenerescência
}

Mário Eduardo Costa Pereira

\begin{abstract}
O Traité des Dégénérescences, de Benedict-Augustin Morel, publicado em 1857, expõe uma teoria da hereditariedade dos transtornos mentais que teria grande influência no pensamento psiquiátrico até o início do século XX. Segundo sua proposição, fortemente impregnada de uma perspectiva religiosa católica, o homem teria sido criado, perfeito, por Deus. A degeneração, correlativa do pecado original, consistiria na transmissão à descendência das taras, vícios e traços mórbidos adquiridos pelos antecessores. À medida que esses estigmas fossem sendo transmitidos através das gerações, seus efeitos tenderiam a se acentuar, levando à completa desnaturação daquela linhagem, chegando até sua extinção pela esterilidade. Em decorrência dessa teoria, muitos projetos de intervenção social de cunho higienista foram desenvolvidos, de modo a impedir a propagação da degeneração da raça.
\end{abstract}

Palavras-chave: Morel, hereditariedade, degenerescência, psicopatologia 
A história da degenerescência constitui uma demonstração concreta de que as relações entre a hereditariedade biológica e a moral são muito mais intricadas do que gostariam de admitir aqueles que buscam apressadamente encontrar, no campo da genética, a famosa values free área sobre a qual fundar a legitimidade médica da psicopatologia.

A idéia de que um fator biológico de natureza hereditária desempenharia um papel maior na etiologia dos transtornos mentais está presente desde os primórdios da psiquiatria contemporânea. Tal elemento hereditário já era destacado por Pinel, em seu Traité médico-philosophique sur l'aliénation mentale, de 1801, como decisivo na predisposição a essa perturbação. Autores como Esquirol, Jean-Pierre Falret e Baillarger, na primeira metade do século XIX, haviam igualmente insistido na importância da hereditariedade como causa da loucura. Para estes, contudo, a herança biológica não era considerada determinante absoluto de um funcionamento mental mórbido, sendo transmitida apenas uma predisposição à alienação mental.

Essa tendência era observada diretamente pela maior freqüência e semelhança clínica dos quadros psiquiátricos apresentados por membros de uma mesma linhagem familiar. Dessa forma, a predisposição à loucura era concebida como específica e similar, no sentido de que os traços transmitidos entre as gerações eram sempre os mesmos para um determinado tipo de condição patológica, segundo a lógica de que o semelhante gera o semelhante (cf. Serpa Jr., 1998).

Correlativamente, diferentes "equações etiológicas" eram propostas pelos diferentes autores, de maneira a integrar, ao lado da herança biológica, os fatores acidentais, biográficos, morais e psicológicos participantes da instalação de um transtorno mental em um determinado indivíduo.

A introdução, por Morel, do conceito de degenerescência, modifica inteiramente o panorama psiquiátrico e as formas de se conceber as modalidades pelas quais o herdado participaria da causação dos transtornos mentais.

Aluno de Jean-Pierre Falret - um dos introdutores da concepção da alienação mental como "uma entidade mórbida" sub-dividida em "formas naturais" (cf. Pereira, 2002), o objetivo maior de Morel era o de estabelecer uma nosografia psiquiátrica fundada na etiologia natural dos transtornos. Ele buscava encontrar a unidade entre o quadro clínico, a evolução e a causa biológica de cada entidade diagnóstica (cf. Bercherie, 1991). Nesse contexto, era-lhe necessário distinguir entre as "causas ocasionais" e as "causas 
determinantes" (p. 72) de cada perturbação. É nesse contexto teórico que a degenerescência hereditária constituiria, a seus olhos, a causa mais importante das doenças psiquiátricas e permitiria uma sistematização coerente e científica dos diagnósticos e classificações (p. 73).

Como assinala Serpa Jr. (1998), a etimologia da palavra "degenerescência" (p. 29) - tal como "degenerar" e "degeneração" - refere-se aos termos latinos genus, generis: raça, em seu sentido mais genérico, evocando, assim a degradação de uma linhagem. Serpa Jr. indica, também, que no tempo de Morel o termo "degenerescência" recobria um amplo campo semântico que incluía: 1) no sentido moral, degradação dos costumes; 2) no sentido anátomo-patológico, a transformação de um tecido corporal normal em um tecido menos diferenciado ou mesmo francamente mórbido (canceroso, por exemplo) e 3) um registro "bioantropológico" (Dupeu, apud Serpa Jr., 1998) que corresponderia "à idéia da existência de um tipo primitivo perfeito que sofreria um processo de decadência gradual e progressiva, tal idéia podendo ter uma referência teológica mais (Morel) ou menos (Buffon) evidente" (p. 30). Esse último uso será central na proposta de Morel (1857), assim explicitada no Traité des dégénérescences: “... a idéia mais clara que podemos fazer da degenerescência da espécie humana é de nos representá-la como um desvio malsão de um tipo ideal" (p. 5).

Tendo sido criado na maior parte de sua infância em um internato religioso sob a tutoria do Abade Dupont, Benedict-Augustin Morel teve uma educação fortemente marcada pela religião católica. Na adolescência, ingressa para o seminário, onde permanecerá até por volta dos vinte anos de idade. Essa intensa formação religiosa exercerá profunda influência sobre sua teoria. Basta lembrar que o livro do Gênesis é explicitamente evocado para sustentar a apresentação de suas teses na introdução de seu Traité des dégénérescences (ibid., p. 2).

Mesmo se a idéia moreliana sobre a degenerescência comporta certas equivocidades e divergências de definição (basta lembrar que o título de sua obra principal remete "às degenerescências", no plural), pode-se afirmar que ela repousa sobre a concepção de que a herança que se transmite através das gerações não se restringe ao plano biológico, mas inclui dimensões morais e de comportamentos - virtuosos ou viciados. Partindo da idéia cristã da perfeição da criação divina, segue-se a hipótese segundo a qual, a partir do pecado original, os erros, males e vícios dos ancestrais transmitem-se às gerações seguintes. Mais do que isso, os efeitos da transmissão hereditária tenderiam a acentuar os traços da tara adquirida pelos predecessores nas gerações subseqüentes. Assim, uma linhagem acometida pela degeneração tenderia a acumular e acentuar seus desvios, o que, em seu extremo, acarretaria na sua esterilidade e extinção. Tratar-se-ia, portanto, de uma forma encontrada pela natureza para eliminar os vícios desenvolvidos e acumulados por uma geração. 
Morel indica diferentes causas para a degenerescência que incluem o abuso do álcool, alimentação deficiente, meio social miserável, imoralidade dos costumes, conduta sexual desregrada, doenças da infância e a própria herança de uma carga de degenerescência (em outros termos, a degenerescência poderia ser herdada ou adquirida).

Nessa perspectiva, a influência concreta da família sobre a criança desempenharia um papel central na instalação da degeneração no indivíduo. Na lição de 16 de janeiro de 1974 de seu curso sobre "O poder psiquiátrico" ministrado no Collège de France, Foucault (2006) lembra que "será chamada de 'degenerada' a criança sobre a qual pesam, a título de estigmas e de marcas, os restos da loucura dos pais e dos antecedentes" (p. 282). Dessa forma, permanece a suspeita de que a degenerescência é a intuição do "efeito de anomalia produzido na criança pelos pais" (ibid.).

É importante lembrar que todas as referências à hereditariedade subjacentes à noção de degenerescência não se apoiavam sobre uma teoria propriamente genética, sendo que mesmo os trabalhos de Mendel sobre as leis da hereditariedade, baseadas em seus experimentos com a hibridação de ervilhas, só seriam apresentados à Sociedade de Ciências Naturais em 1865 e que a própria noção de "gene" só iria se consolidar no início do século XX.

A psiquiatria e as concepções científicas sobre a hereditariedade dos transtornos mentais estiveram profundamente marcadas, na segunda metade do século XIX, pela teoria da degenerescência. A potência explicativa da noção de degenerescência parecia não conhecer limites e todos os traços mórbidos ou aberrantes podiam ser compreendidos à luz dessa proposição. A doutrina de Morel recorria, por exemplo, à idéia de uma hereditariedade "dessemelhante": determinados traços de degeneração em um ancestral pode se manifestar de maneira diferente em seus descendentes. Assim, a conduta desregrada do avô poderia constituir a evidência da base hereditária para a alienação mental do neto. Freud criticará explicitamente esse ponto de vista em seu artigo escrito em francês, L'hérédité et l'étiologie des névroses, de 1896.

Com a teoria da degenerescência, a nascente disciplina psiquiátrica encontrava um sólido referencial sobre o qual ancorar suas pretensões a pertencer à medicina de pleno direito. A adesão às teses morelianas foi maciça entre os alienistas e muitos foram seus continuadores no plano teórico. $\mathrm{O}$ mais importante entre estes certamente foi Valentin Magnan. Seus estudos orientaram-se no sentido de criticar o caráter excessivamente metafísico, e mesmo religioso, da teoria de Morel. Magnan (apud Serpa Jr., 1998) considerava que o ponto de vista segundo o qual o homem seria originário de um ancestral ideal era cientificamente insustentável e que a noção de degenerescência não poderia ser considerada mórbida em si mesma, significando apenas que, em relação a seus antecessores, aque- 
le indivíduo seria "constitucionalmente diminuído na sua resistência psico-física" e nele só se realizam "incompletamente as condições biológicas da luta hereditária pela vida" (p. 139). A instalação efetiva do distúrbio dependeria, portanto, das condições ambientais e existenciais do indivíduo.

Os esforços de Magnan convergiam para a delimitação de uma teoria da degenerescência compatível com a observação clínica imediata e sua validação empírica. Apoiado em uma estranha fusão entre o darwinismo que chegava na psicologia francesa pela via de Ribot e de Férrus, e a tradição lamarkista da ciência de seu país, Magnan (apud Serpa Jr.) rejeitava a idéia de que "a perfeição deve ser procurada na origem" (p. 140). Esta não poderia ser pensada senão no final do processo evolutivo da espécie.

Nessa nova versão da degenerescência, as proposições relativas a essa forma de conceber a questão da hereditariedade deveriam ser expostas de maneira positiva e em sintonia com a ciência biológica praticada pela medicina da época. Conforme havíamos assinalado em outro artigo (Pereira, 1999), "Magnan propõe uma correlação mais estreita entre as alterações psicopatológicas e lesões específicas do sistema nervoso, evitando as grandes generalizações inespecíficas de certas concepções etiológicas anteriores " (p. 160).

Uma das preocupações centrais de Benedict-Augustin Morel era a concepção terapêutica a ser deduzida dos pressupostos da teoria da degenerescência, em particular as ações sanitárias e higienistas a serem implementadas pela autoridade pública com o objetivo de impedir a propagação das tendências degeneradas entre a população. Em diversos países do mundo, programas de saúde coletiva foram desenvolvidos e implementados em torno de noções como "manutenção da pureza da raça" e "estímulo e manutenção dos bons costumes". No Brasil, no início do século XX, todo um programa de combate à mestiçagem e de "arianização da raça brasileira", sustentado notadamente pela Liga Brasileira de Higiene Mental, teve nas teses da degenerescência seu fundamento teórico e ideológico (para um maior aprofundamento desse debate, remetemos a Costa, 1989. Para o estudo da influência da teoria da degenerescência no pensamento psiquiátrico e psicopatológico de Franco da Rocha, sugerimos França Pereira, 2003).

\section{Referências}

Bercherie, P. Histoire et structure du savoir psychiatrique: les fondements de la clinique - I. Tournai: Editions Universitaires, 1991.

Costa, J.F. História da psiquiatria no Brasil. 4. ed. Rio de Janeiro: Xenon, 1989.

Foucault, M. O poder psiquiátrico. São Paulo: Martins Fontes, 2006. 
França Pereira, L.M. Franco da Rocha e a teoria da degeneração. Revista Latinoamericana de Psicopatologia Fundamental, São Paulo, v. VI, n. 3, p. 154-163, set.2003.

Freud, S. A hereditariedade e etiologia das neuroses. In: Edição Standard Brasileiras das Obras Psicológicas Completas de Sigmund Freud. Rio de Janeiro: Imago, 1976. v. III, p. 165-179.

Morel, B.-A. Traité des dégénérescences physiques, intelectuelles et morales de l'espèce humaine et les causes qui produisent ces variétés maladives. Paris: Baillière, 1857.

Pereira, M.E.C. De uma hereditariedade não-fatalista: o endógeno e o Typus melancolicus, segundo Tellenbach. Revista Latinoamericana de Psicopatologia Fundamental, São Paulo, v. II, n. 4, p. 159-163, dez.1999.

. A loucura circular de Falret e as origens do conceito de psicose maníacodepressiva. Revista Latinoamericana de Psicopatologia Fundamental, São Paulo, v. V, n. 4, p. 125-129, dez.2002.

SERPA Jr., O.D. Mal-estar na natureza. Belo Horizonte: Te Corá Editora, 1998.

Resumos

(Morel y la cuestión de la degeneración)

El Traité des Dégénérescences, de Benedict-Augustin Morel, publicado en 1857, expone una teoría del carácter hereditario de los trastornos mentales que tuvo gran influencia en el pensamiento psiquiátrico hasta el inicio del siglo XX. Segundo su propuesta, fuertemente impregnada de una perspectiva religiosa católica, el hombre habría sido criado perfecto por Dios. A degeneración, correlativa del pecado original, consistiría en la transmisión a la descendencia de las taras, vicios e trazos mórbidos adquiridos por los antecesores. En la medida que estos estigmas fuesen sendo transmitidos a través de las generaciones, sus efectos tenderían a acentuarse, llevando a la completa desnaturalización de aquel linaje, llegando hasta su extinción por esterilidad. A consecuencia de esta teoría, muchos proyectos de intervención social de cuño higienista fueron desarrollados, como modo de impedir la propagación de la degeneración de la raza.

Palabras clave: Morel, herencia, degeneración, psicopatología

(Morel et la question de la dégénérescence)

Le Traité des Dégénérescences de Benedict-Augustin Morel, publié en 1857, présente une théorie de l'hérédité des troubles mentaux qui aura grande influence sur la pensée psychiatrique jusqu'au début du XXe siècle. Selon sa proposition, fortement 
influencée par une perspective religieuse catholique, l'homme aurait été crée comme un être parfait par Dieu. La dégénérescence, corrélative du pêché originel, consisterait dans la transmission des tares, vices et traits morbides, acquis par les antécesseurs, à leurs descendants. Au fur et à mesure que ces caractéristiques sont transmises aux générations suivantes, leurs effets s'intensifient, jusqu'à la complète dénaturation de cette lignée, qui arrive à l'extinction par la stérilité. En conséquence de cette théorie, un grand nombre de projets d'intervention sociale de caractère hygiéniste furent développés, cherchant à empêcher la propagation de la dégénération de la race.

Mots clés: Morel, hérédité, dégénérescence, psychopathologie

(Morel and the question of degeneration)

The Traité des Degenerations, by Benedict-Augustin Morel, published in 1857, contains a theory of the heredity of mental disorders that was to have considerable influence on psychiatric thought until the early 20th century. According to Morel's proposition, strongly impregnated with a religious Catholic perspective, man was created perfect by God. Degeneration, a correlative of original sin, consists of the transmission of evil wishes, bad habits and morbid traits to an individual's predecessors. As these stigmas are transmitted from one generation to the next, their effects tend to grow, leading to complete de-naturation of the lineage and causing its eventual extinction through sterility. Consequent to this theory, numerous projects of social intervention in the area of hygiene and sanitation were put into pratice in order to avoid more serious degeneration of the human race in the future.

Key words: Morel, heredity, degeneration, psychopathology

Versão inicial recebida em julho de 2008 Versão aprovada para publicação em julho de 2008

\section{Mário Eduardo Costa Pereira}

Psiquiatra; psicanalista e professor do Depto. de Psicologia Médica e Psiquiatria da Universidade Estadual de Campinas - Unicamp (Campinas, SP, Brasil); doutor em Psicopatologia Fundamental e Psicanálise pela Universidade Paris 7 (Paris, França); diretor do Laboratório de Psicopatologia Fundamental da Unicamp; professor do Departamento de Psicanálise do Instituto Sedes Sapientiae (São Paulo, SP, Brasil); membro da Associação Universitária de Pesquisa em Psicopatologia Fundamental (São Paulo, SP, Brasil); autor dos livros Pânico e desamparo (São Paulo: Escuta, 1999) e Psicopatologia dos ataques de pânico (São Paulo: Escuta, 2003).

Rua Carolina Prado Penteado, 725 - Nova Campinas

13092-470 Campinas, SP, Brasil

Fone: (19) 3254-5064 / 3254-1982 / 3289-4819 (Unicamp)

e-mail: marioecpereira@uol.com.br 